Research Paper

\title{
FGFR4 and TGF- $\beta$ I Expression in Hepatocellular Carcinoma: Correlation with Clinicopathological Features and Prognosis
}

\author{
Zhixin Chen ${ }^{* 1}$, Bao Xie ${ }^{* 1}$ 2, Qinhua Zhu ${ }^{* 1}$, Qinghai Xia ${ }^{* 1}$, Songmin Jiang ${ }^{* 3}$, Ruoyu Cao ${ }^{*}$, Lihua Shi ${ }^{1}$, Dansi \\ $\mathrm{Qi}^{2}$, Xiaokun Li1 ${ }^{1}$, Lin Cai ${ }^{\circledR}$ \\ 1. Department of Biopharmaceutics, School of Pharmacy, Wenzhou Medical University, Zhejiang, Wenzhou (China) \\ 2. Department of Pathology, the Second Affiliated Hospital of Wenzhou Medical University, Zhejiang, Wenzhou (China) \\ 3. Department of Pharmacy, Wenzhou Ruian People's Hospital, Zhejiang, Wenzhou (China) \\ 4. Department of Pediatrics, Cangzhou Central Hospital, Hebei, Cangzhou (China). \\ * These authors contributed equally to this work.
}

$\square$ Corresponding author: Lin Cai, Associated Professor and Chief, Department of Biopharmaceutics, School of Pharmacy, Wenzhou Medical University, Chashan Wenzhou 325035, Zhejiang Province, China. Tel: 086-577-86699350 Fax: 086-577-86699350 E-mail: cailin@wzmc.edu.cn; cailin33@gmail.com.

( ) Ivyspring International Publisher. This is an open-access article distributed under the terms of the Creative Commons License (http://creativecommons.org/ licenses/by-nc-nd/3.0/). Reproduction is permitted for personal, noncommercial use, provided that the article is in whole, unmodified, and properly cited.

Received: 2013.06.09; Accepted: 2013.10.17; Published: 2013.11.12

\begin{abstract}
Objective: To investigate the expression and correlation of transforming growth factor- $\beta$ I (TGF- $\beta \mathrm{I}$ ) and fibroblast growth factor receptor 4 (FGFR4) in human hepatocellular carcinoma (HCC) and the relationship with clinicopathological features and prognosis.

Materials and methods: The expression of TGF- $\beta$ I and FGFR4 in 126 HCC samples was detected immunohistochemically. Combined with clinical postoperative follow-up data, the expression of TGF- $\beta$ I and FGFR4 in HCC and the relationship with the prognosis of patients were analyzed by statistically.

Results: The positive expression rate of TGF- $\beta$ I was $84.1 \%$ (I06/I26) in tumors, and that in peritumoral liver tissues was $64.3 \%(8 \mathrm{I} / \mathrm{I} 26)$; the positive expression rate of FGFR4 in tumors was $74.6 \%(94 / 126)$ and that in peritumoral liver tissues was $57.1 \%(72 / 126)$. The expression of TGF- $\beta$ I and FGFR4 in the carcinoma tissues was significantly higher than that in peritumoral liver tissues ( $p$ $<0.05)$. Intratumoral TGF- $\beta$ I and FGFR4 expression was associated with TNM stage $(p<0.05)$. TGF- $\beta$ I and FGFR4 expression levels didn't significantly correlate with other clinicopathological parameters, including age, sex, tumor size, serum AFP level, tumor differentiation, lymph node metastasis, etc. $(p>0.05)$. TGF- $\beta$ I expression was positively correlated with FGFR4 expression $(r$ $=0.595, p<0.05$ ). Patients with positive FGFR4 or TGF- $\beta$ I expression had shorter overall survival compared with negative expression $(p<0.05)$.

Conclusions: The expression of TGF- $\beta$ I and FGFR4 could make synergy on the occurrence and progression of HCC, and may be used as prognosis indicators for HCC patients.
\end{abstract}

Key words: TGF- $\beta 1$, FGFR4, hepatocellular carcinoma, immunohistochemistry, prognosis.

\section{Introduction}

Hepatocellular carcinoma (HCC), which is the sixth most common cancer in terms of its incidence rate and the third most common cause of cancer-related deaths globally, is responsible for about 600,000 deaths annually [1]. The five-year survival rate of this cancer is merely $7 \%$. Curative therapies of surgical treatment, including hepatic resection and liver transplantation, improve the chances of survival of patients with HCC [2-4]. However, a limited number of patients can be treated with surgery because of 
the damage to liver function. The prognosis for most patients remains poor after surgery for multicentric recurrence and extrahepatic metastasis [5-6]. This disappointing outcome clearly indicates that the current knowledge regarding diagnosis, prevention, and treatment of liver cancer is insufficient, which strongly suggests a pressing need for further innovative research to control this devastating disease.

Transforming growth factor- $\beta 1$ (TGF- $\beta 1$ ) has been described as a prototypical multifunctional cytokine, participating in the regulation of vital cellular processes such as cell proliferation, differentiation and angiogenesis as well as a number of basic physiological functions including tissue development, immunosuppression and extracellular matrix formation. Recently, another essential function of TGF- $\beta 1$ that has come to light is its role as a tumor suppressor in various types of cells. Research has demonstrated that TGF- $\beta 1$ plays a dual role in mouse skin carcinogenesis as well as in other human and murine cancer models [7-11]. However, TGF- $\beta 1$ has also been shown to facilitate the epithelial-to-mesenchymal transition of hepatocytes that in turn participates in the progression of liver fibrosis [12]. The effect of TGF- $\beta 1$ in different tumors and tumor cell strains is complex due to the specific environment of the cell and the underlying mechanisms are unclear.

Members of the FGF receptor (FGFR) family of receptor tyrosine kinases are of tremendous significance in a variety of human cancers. FGFR4 is overexpressed in malignant melanoma [13], breast cancer [14], renal cell carcinoma [15] and hepatocellular carcinoma (HCC) [16]. Although its role in oncogenesis remains to be fully elucidated, several findings provide evidence for a modulatory role of FGFR4 in HCC development and progression. FGFR4 is the predominant FGFR isoform present in human hepatocytes [17]. High FGFR4 transcript levels have also been previously reported in liver tissue [18]. Together, these findings suggest that FGFR4 may be a novel therapeutic target in the diagnosis and treatment of this disease.

Both TGF- $\beta 1$ and FGFR4 could promote the invasiveness and metastasis of tumor only under the specific cell surroundings. Whether or not these two molecules exist some relationship, there have no report about it. In the present study, we first hypothesized the role of combined expression of two kinds of oncoproteins, TGF- $\beta 1$ and FGFR4, in the genesis and development of liver cancer. This study was designed to determine the expression levels of TGF- $\beta 1$ and FGFR4 in HCCs and adjacent normal tissues by immunohistochemistry in order to assess their relationship. We further investigated the relationship be- tween TGF- $\beta 1$ and FGFR4 expression and the presence of clinicopathological pathological features. At the same time we sought to predict the prognosis of HCC from the results.

\section{Materials and methods}

\section{Patients and specimens}

Cancerous tissues and surrounding noncancerous hepatic parenchyma were obtained from 126 primary HCC patients who underwent curative resection surgery at the Second Affiliated Hospital of Wenzhou Medical College Yuying Children's Hospital, from January 2002 to December 2007. Approval for all studies was obtained from the Second Affiliated Hospital of Wenzhou Medical College, Yuying Children's Hospital Ethics Committee. Informed consent was obtained from all patients prior to sample collection. For inclusion, patients required suitable formalin-fixed, paraffin-embedded tissue specimens and complete clinicopathologic and follow-up data. Samples were obtained from 92 men and 34 women aged 29-80 years. Tumors were staged according to the tumor, lymph node, and metastasis (TNM) classification system of the 2002 International Union against Cancer. The histologic grade of tumor differentiation was assigned using the Edmondson grading system. Tumor size was based on the largest dimension of the tumor specimen. Vascular invasion was determined by microscopic examination of the resected specimen. In the corresponding noncancerous parenchyma, cirrhosis was found in 50 patients $(40 \%)$. Detailed clinicopathologic features of the HCC cases are shown in Table 1.

\section{Immunohistochemical staining}

An immunohistochemical analysis was performed on paraffin-embedded sections using the Elivision plus system (Maixin Bio, Fuzhou, China) following the manufacturer's instructions. The sections were boiled in retrieval solution to expose the antigens. Rabbit anti-human TGF- $\beta 1$ polyclonal antibody (Maixin Bio, Fuzhou, China), rabbit anti-human FGFR4 polyclonal antibody and mouse anti-human FGF19 monoclonal antibody (Santa Cruz Biotechnology, Santa Cruz, CA, USA) were applied as primary antibodies to the sections at a dilution of 1:50. The section slides were incubated with primary antibodies overnight at $4{ }^{\circ} \mathrm{C}$ and then washed to remove excess antibody with phosphate-buffered saline (PBS). The Elivision plus system was used to detect bound antibodies. Reaction products were visualized by incubation with 3, 3'-diaminobenzidine. Sections were dehydrated, counterstained with hematoxylin, and mounted. Negative controls were treated identically 
except that the primary antibody was replaced by PBS.

\section{Immunohistochemical scoring}

Immunohistochemical results for TGF- $\beta 1$ and FGFR4 were evaluated by two investigators separately in all the specimens in a blinded manner. The positive signals of TGF- $\beta 1$ and FGFR4 expression stained yellow or brown, mainly in the cytoplasm. Buffy staining of the cell membrane, cytoplasm or nuclei was positive for each of them. We randomly selected ten high-power fields (magnification, $\times 400$; 100 cells/high-power field) and counted 1, 000 cells in each core [20]. The percentage of positive tumor cells was determined by each observer, and the average of the two scores was calculated. In this study, the percentage of positive cells expressing TGF- $\beta 1$ and FGFR4 were categorized as follows: $<10 \%(-)$ and $\geq$ $10 \%(+)$ for TGF- $\beta 1[21],<30 \%(-)$ and $\geq 30 \%(+)$ for FGFR4 [22].

\section{Statistical analysis}

The Pearson Chi-square test or Fisher's exact test was used to compare categorical variables; and correlation between TGF- $\beta 1$ and FGFR4 was evaluated using the Spearman rank correlation coefficient test. Using the method described by Kaplan-Meier, overall survival curves were obtained from the date of operation to the last visit or death. A Cox proportional hazards regression model was used for multivariate analysis of survival. All statistical analyses were performed with SPSS 15.0 software (SPSS Inc, Chicago, IL, USA). P values of less than 0.05 were considered statistically significant.

\section{Results}

\section{Clinicopathological data}

Among the 126 patients studied, 92 (73\%) were men and $34(27 \%)$ were women, with a mean age of 55.8 years (range, 29 to 80 years). 41 (32.5\%) of the studied tumors were classified as well differentiated HCC, $61(48.4 \%)$ as moderately differentiated, and 24 $(19.1 \%)$ as poorly differentiated. There were 24 cases $(19 \%)$ of lymph node metastasis and 35 cases $(27.8 \%)$ of vascular invasion. 78 cases $(61.9 \%)$ had TNM stage I - II, and 48 cases (38.1\%) had TNM stage III - IV. Based on the MRI examination, 75 cases were categorized as small tumor (tumor size $<5 \mathrm{~cm}$ ) and 51 were large tumor (tumor size $\geq 5 \mathrm{~cm}$ ). The follow-up period was defined as the interval from the date of operation to that of the last visit or the patient's death. Deaths from other causes were treated as censored cases.

Table I. Correlations between of TGF- $\beta$ I and FGFR4 expression and clinicopathologic features.

\begin{tabular}{|c|c|c|c|c|c|c|c|c|c|}
\hline \multirow{2}{*}{$\begin{array}{l}\text { Clinicopathological } \\
\text { parameters }\end{array}$} & \multirow[b]{2}{*}{$\mathrm{n}$} & \multicolumn{4}{|c|}{ Expression of TGF- $\beta 1$} & \multicolumn{4}{|c|}{ Expression of FGFR4 } \\
\hline & & $\begin{array}{l}\text { positive } \\
(\mathrm{n}=106)\end{array}$ & $\begin{array}{l}\text { negative } \\
(\mathrm{n}=20)\end{array}$ & $x^{2}$ & $\mathrm{P}$ & $\begin{array}{l}\text { positive } \\
(\mathrm{n}=94)\end{array}$ & $\begin{array}{l}\text { negative } \\
(\mathrm{n}=32)\end{array}$ & $x^{2}$ & $\mathrm{P}$ \\
\hline \multicolumn{10}{|l|}{ Age $(55.83 \pm 12.97)$} \\
\hline$<56$ years & 58 & 46 & 12 & 1.867 & 0.172 & 40 & 18 & 1.803 & 0.179 \\
\hline$\geq 56$ years & 68 & 60 & 8 & & & 54 & 14 & & \\
\hline \multicolumn{10}{|l|}{ Gender } \\
\hline Male & 92 & 81 & 11 & 3.916 & 0.048 & 72 & 20 & 2.407 & 0.121 \\
\hline Female & 34 & 25 & 9 & & & 22 & 12 & & \\
\hline \multicolumn{10}{|l|}{ Tumor size } \\
\hline$<5 \mathrm{~cm}$ & 75 & 61 & 14 & 1.083 & 0.298 & 52 & 23 & 2.716 & 0.099 \\
\hline$\geq 5 \mathrm{~cm}$ & 51 & 45 & 6 & & & 42 & 9 & & \\
\hline \multicolumn{10}{|l|}{ AFP } \\
\hline$<20 \mathrm{ng} / \mathrm{ml}$ & 93 & 80 & 13 & 0.954 & 0.329 & 70 & 23 & 0.083 & 0.773 \\
\hline$\geq 20 \mathrm{ng} / \mathrm{ml}$ & 33 & 26 & 7 & & & 24 & 9 & & \\
\hline \multicolumn{10}{|c|}{ Tumor Differentiation } \\
\hline Well & 41 & 32 & 9 & 2.196 & 0.334 & 30 & 11 & 2.674 & 0.263 \\
\hline Moderately & 61 & 52 & 9 & & & 43 & 18 & & \\
\hline Poorly & 24 & 22 & 2 & & & 21 & 3 & & \\
\hline \multicolumn{10}{|c|}{ lymph node metastasis } \\
\hline Present & 24 & 23 & 1 & 1.661 & 0.197 & 19 & 5 & 0.326 & 0.568 \\
\hline Absent & 102 & 93 & 19 & & & 75 & 27 & & \\
\hline \multicolumn{10}{|l|}{ Vascular invasion } \\
\hline Present & 35 & 33 & 2 & 3.745 & 0.053 & 28 & 7 & 0.745 & 0.388 \\
\hline Absent & 91 & 73 & 18 & & & 66 & 25 & & \\
\hline \multicolumn{10}{|l|}{ TNM stage } \\
\hline I-II & 78 & 59 & 19 & 10.954 & 0.001 & 53 & 25 & 4.747 & 0.029 \\
\hline III-IV & 48 & 47 & 1 & & & 41 & 7 & & \\
\hline
\end{tabular}




\section{Immunohistochemical analysis}

TGF- $\beta 1$ and FGFR4 were localized mainly in the cytoplasm of tumor cells or hepatocytes. Most of the stroma cells were negative for anti-TGF- $\beta 1$ and anti-FGFR4 staining, although sporadic positive staining on these cells was also observed (Fig. 1C, Fig. 1F). TGF- $\beta 1$ was also partly expressed in fibroblastic cells. Of the 126 samples, 106 (84.1\%) samples showed high intratumoral and $81(64.3 \%)$ samples high peritumoral TGF- $\beta 1$ expression (Table 2). There was intratumoral FGFR4 expression in 94 (74.6\%) samples and peritumoral expression in 72 (57.1\%) samples (Table 3). Both Fig. 1 and Fig. 2 show the results of TGF- $\beta 1$ and FGFR4 staining, respectively, of intratumoral and peritumoral tissue. The expression of TGF- $\beta 1$ and FGFR4 in the carcinoma tissues was significantly higher than that in peritumoral liver tissues $(p<0.05)$.

TGF-B1
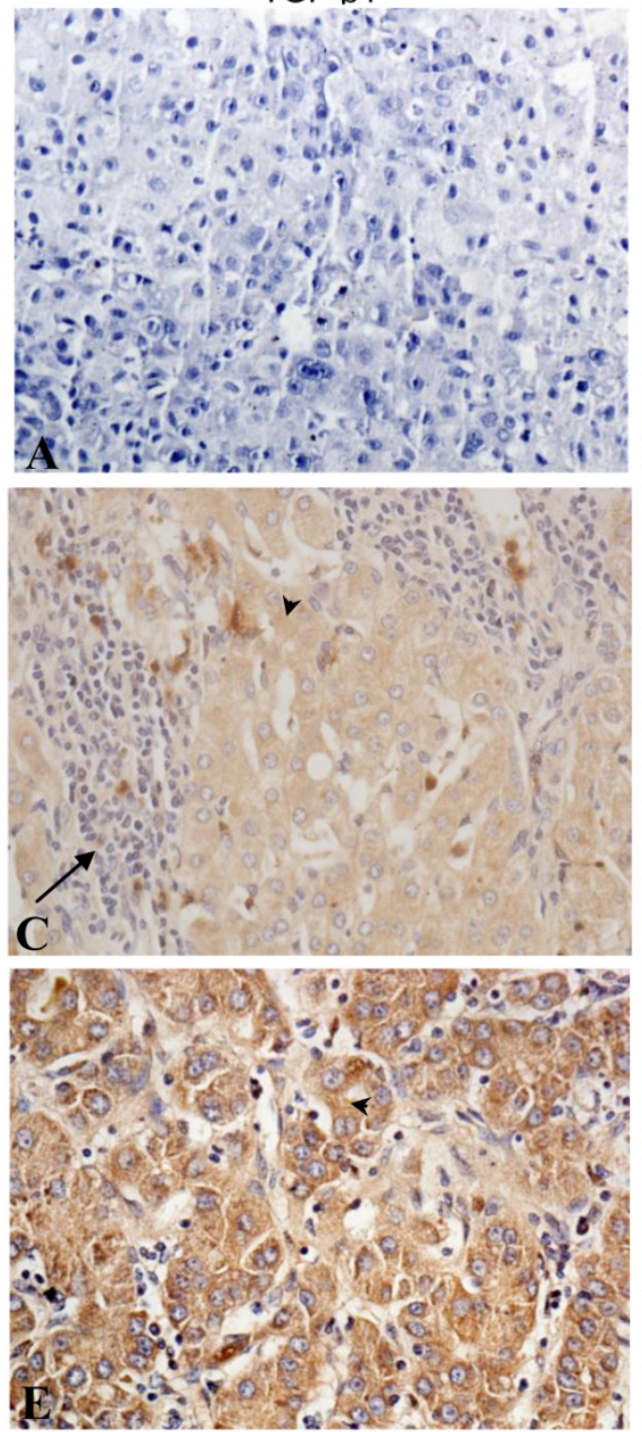

Table 2. Expression of TGF- $\beta$ I in cancer tissues and paracancer tissues.

\begin{tabular}{|c|c|c|c|c|c|c|}
\hline \multirow[t]{2}{*}{ Group } & \multirow[t]{2}{*}{$n$} & \multicolumn{3}{|c|}{ Expression of TGF- $\beta 1$} & \multirow[t]{2}{*}{$x^{2}$} & \multirow[t]{2}{*}{$P$} \\
\hline & & Positive & Negative & $\begin{array}{l}\text { Positive rate } \\
(\%)\end{array}$ & & \\
\hline $\begin{array}{l}\text { Paracancer Tis- } \\
\text { sues }\end{array}$ & 126 & 81 & 45 & 64.29 & 12.958 & 0.000 \\
\hline Cancer Tissues & 126 & 106 & 20 & 84.13 & & \\
\hline
\end{tabular}

Table 3. Expression of FGFR4 in cancer tissues and paracancer tissues.

\begin{tabular}{|c|c|c|c|c|c|c|}
\hline \multirow[t]{2}{*}{ Group } & \multirow[t]{2}{*}{$\mathrm{n}$} & \multicolumn{3}{|c|}{ Expression of FGFR4 } & \multirow[t]{2}{*}{$x^{2}$} & \multirow[t]{2}{*}{$P$} \\
\hline & & Positive & $\begin{array}{l}\text { Nega- } \\
\text { tive }\end{array}$ & $\begin{array}{l}\text { Positive } \\
\text { rate (\%) }\end{array}$ & & \\
\hline $\begin{array}{l}\text { Paracancer Tis- } \\
\text { sues }\end{array}$ & 126 & 72 & 54 & 57.14 & 8.544 & 0.003 \\
\hline Cancer Tissues & 126 & 94 & 32 & 74.60 & & \\
\hline
\end{tabular}
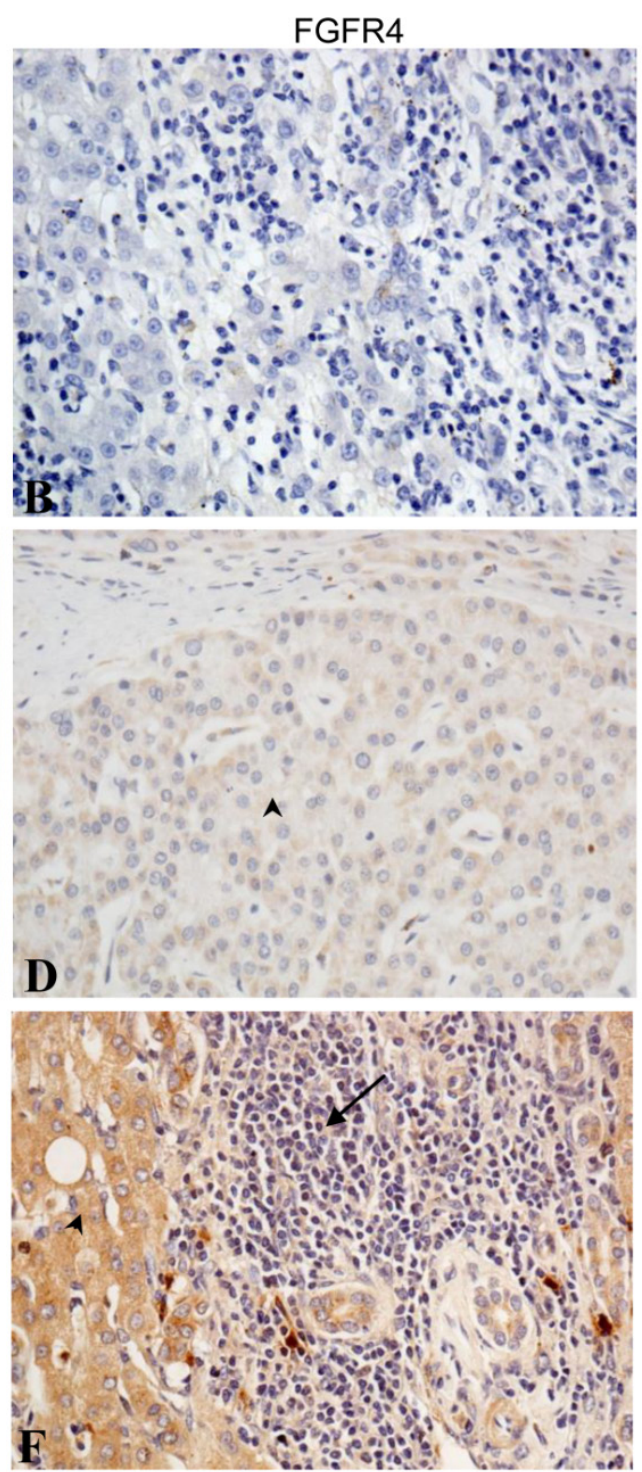

Fig I. Immunohistochemical staining of TGF- $\beta$ I and FGFR4 in liver cancer tissues. No staining was detected for (A) TGF- $\beta$ I and (B) FGFR4 in the blank control group. (C) Weak cytoplasmic staining of TGF- $\beta$ I in tumor cells and some stromal cells. (D) Weak FGFR4 staining in tumor cells. (E) High TGF- $\beta$ I staining in tumor cells. (F) High FGFR4 staining in tumor cells and weak staining in stromal cells. (Arrowhead indicated the tumor cells and arrow indicated the stromal cells). (All photos are shown at $\times 400$ magnification). 

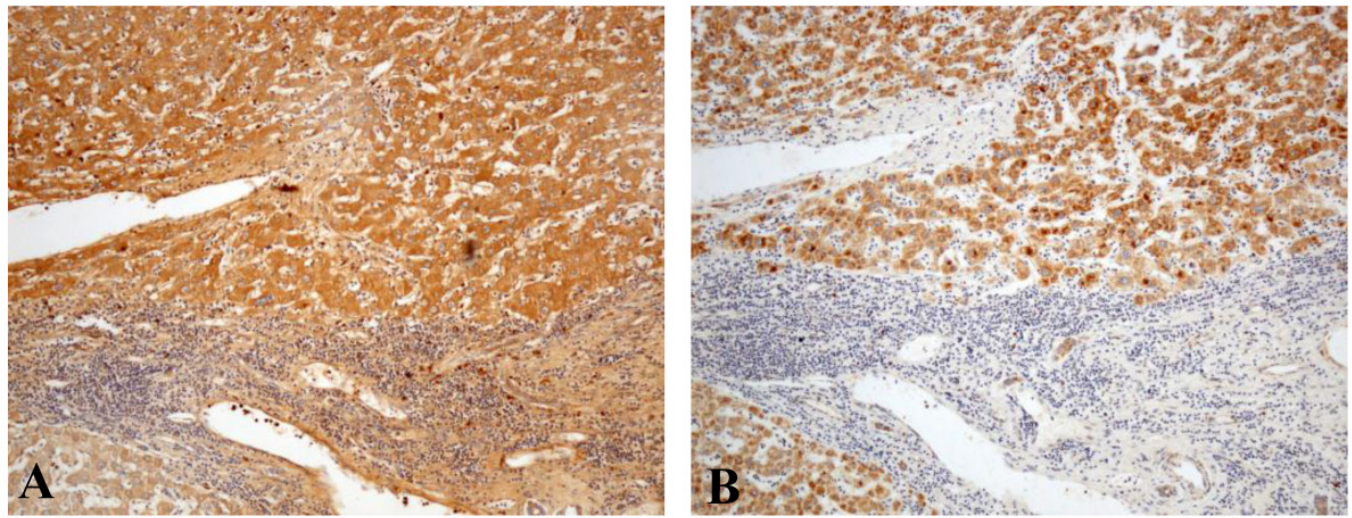

Fig 2. Comparison of the immunostaining patterns between (A) TGF- $\beta$ I and (B) FGFR4 in liver cancer tissues $(\times 100)$.

A

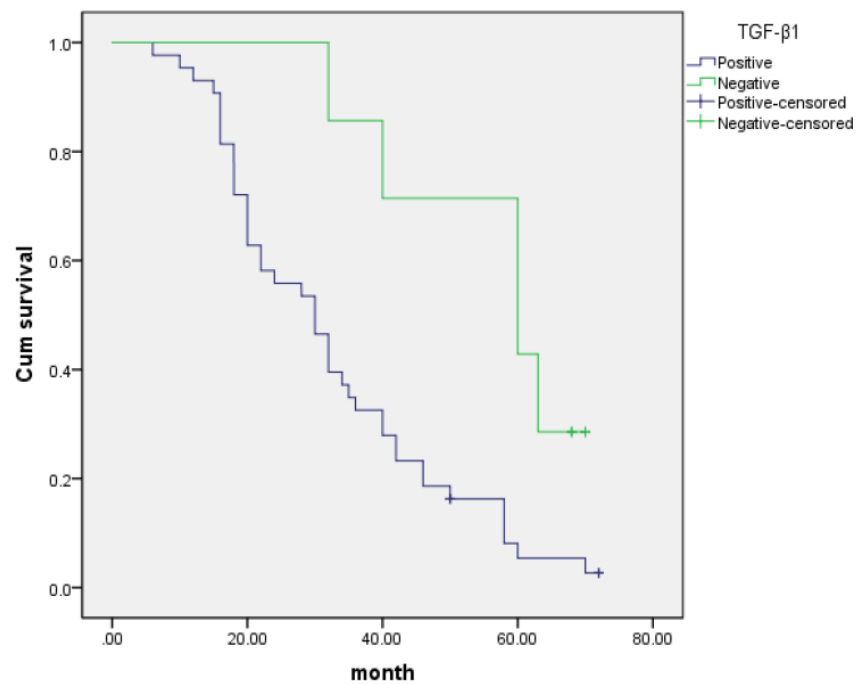

B

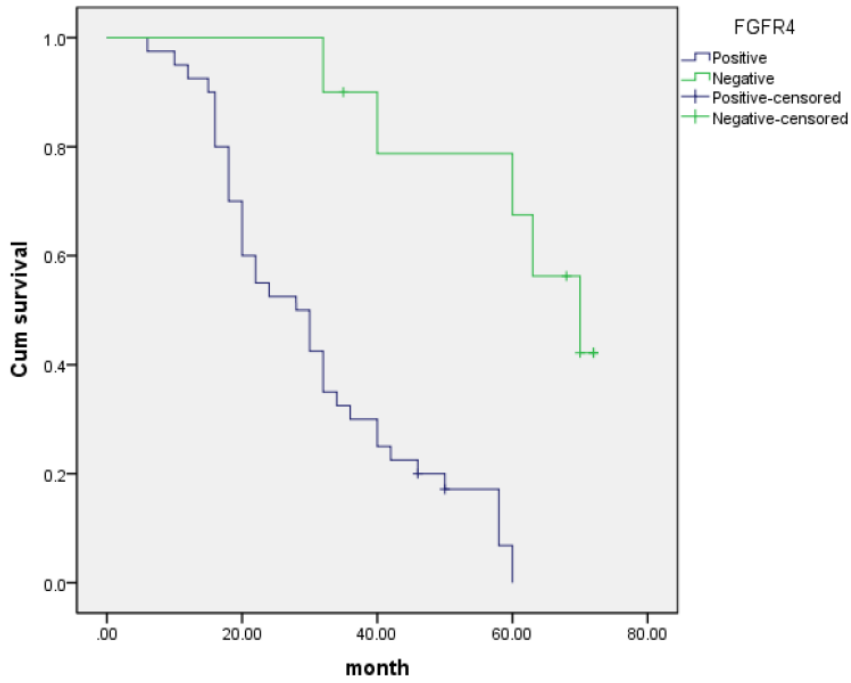

Fig 3. Kaplan- Meier curves with univariate analyses (log- rank) for patients with (A) negative TGF- $\beta$ I expression versus positive TGF- $\beta$ I expression and (B) negative FGFR4 expression versus positive FGFR4 expression in hepatocarcinoma patients.

\section{Correlations between TGF- $\beta$ I and FGFR4 expression and clinicopathologic features}

Univariate analysis suggested that staining with TGF- $\beta 1$ bore no relation to age and sex $(p>0.05)$; while the expression of FGFR4 also showed no significantly higher levels in older patients than in younger patients $(p>0.05)$. We also found that TGF- $\beta 1$ and FGFR4 had no significant correlation with other prognostic factors, such as tumor size, serum AFP level, tumor differentiation, lymph node metastasis and vascular invasion $(p>0.05)$. In contrast, an association was apparent between TGF- $\beta 1$ and FGFR4 staining and disease stage (Table 1). Tumors of patients with high TGF- $\beta 1$ and FGFR4 expression levels were more likely to be at a higher TNM stage ( $p=0.001$ and 0.029 , respectively).

\section{Correlations between TGF- $\beta$ I and FGFR4 expression and prognosis}

The five year survival rate for TGF- $\beta 1$ negative expression was $45.6 \%$, median survival time was 50.4 months. The five year survival rate for TGF- $\beta 1$ positive expression was $8.5 \%$, median survival time was 32.3 months. Patients with positive TGF- $\beta 1$ expression had shorter OS compared to those with negative TGF- $\beta 1$ expression according to the Kaplan-Meier analyses $(p<0.05)$ (Fig. 3A).

The five year survival rate for FGFR4 negative expression was $70.1 \%$, median survival time was 51.2 months. The five year survival rate for FGFR4 positive expression was $8.3 \%$, median survival time was 29.4 months. Survival analyses using the Kaplan-Meier method showed that patients with positive FGFR4 expression had shorter overall survival (OS) compared to those with negative FGFR4 expression $(p<$ 0.05) (Fig. 3B). 


\section{Multivariate analysis of clinicopathological paramaters and prognosis}

The factors with possible prognostic effects in hepatocarcinoma were analyzed by Cox regression analysis. The study revealed that vascular invasion $(p=0.003)$, expression of TGF- $\beta 1(p=0.002)$ and FGFR4 $(p=0.001)$ were independent prognostic factors of patients with hepatocarcinoma (Table 4). However, age, sex, tumor size, serum AFP level, tumor differentiation, lymph node metastasis, and TNM stage had no prognostic value.

Table 4. Multivariate analysis of hepatocarcinoma patients prognosis.

\begin{tabular}{lllllll}
\hline & $\mathrm{B}$ & $\mathrm{SE}$ & Wald & $\mathrm{df}$ & Sig & Exp (B) \\
\hline Vasular invasion & 2.014 & 0.320 & 8.217 & 1 & 0.003 & 8.115 \\
TGF- $\beta 1$ & 3.313 & 0.786 & 11.841 & 1 & 0.002 & 10.226 \\
FGFR4 & 2.616 & 0.687 & 10.624 & 1 & 0.001 & 9.337 \\
\hline
\end{tabular}

\section{Association among expression of TGF- $\beta$ I and FGFR4}

Ninety one hepatocarcinoma cases had positive expression of both TGF- $\beta 1$ and FGFR4, and seventeen hepatocarcinoma cases had negative expression of both TGF- $\beta 1$ and FGFR4. Correlation analysis of these potential biomarkers revealed that intratumoral FGFR4 correlated with high intratumoral TGF- $\beta 1$ expression $(r=0.595, p<0.05)$ (Table 5). We also detected the outcomes of TGF- $\beta 1$-positive/ FGFR4-positive, TGF- $\beta 1$-positive/FGFR4-negative, TGF- $\beta 1$-negative/FGFR4-positive, and TGF- $\beta 1$ negative/FGFR4-negative hepatocarcinoma patients, and we found that there was a significant difference in overall comparisons $\left(X^{2}=34.7, p=0.000\right.$, Fig 4$)$. The mean survival time were $30.2 \pm 1.76$ months for TGF- $\beta 1$-positive/FGFR4-positive group, $43.3 \pm 5.44$ months for TGF- $\beta 1$-positive/FGFR4-negative, 39.5 \pm 3.32 months for TGF- $\beta 1$-negative/FGFR4positive, 50.2+3.91 months for TGF- $\beta 1$-negative/ FGFR4-negative, respectively.

Table 5. The relationship between TGF- $\beta$ I and FGFR4 expression in HCCs.

\begin{tabular}{|c|c|c|c|c|c|}
\hline & \multirow[b]{2}{*}{$\mathrm{n}$} & \multicolumn{2}{|c|}{ FGFR4 expression } & \multirow[t]{2}{*}{$\mathrm{r}^{* *}$} & \multirow[t]{2}{*}{$P^{*}$} \\
\hline & & $\begin{array}{l}\text { Positive } \\
(\mathrm{n}=94)\end{array}$ & $\begin{array}{l}\text { Negative } \\
(\mathrm{n}=32)\end{array}$ & & \\
\hline \multicolumn{6}{|c|}{ TGF- $\beta 1$ expression } \\
\hline Positive & 106 & 91 & 15 & 0.595 & 0.000 \\
\hline Negative & 20 & 3 & 17 & & \\
\hline
\end{tabular}

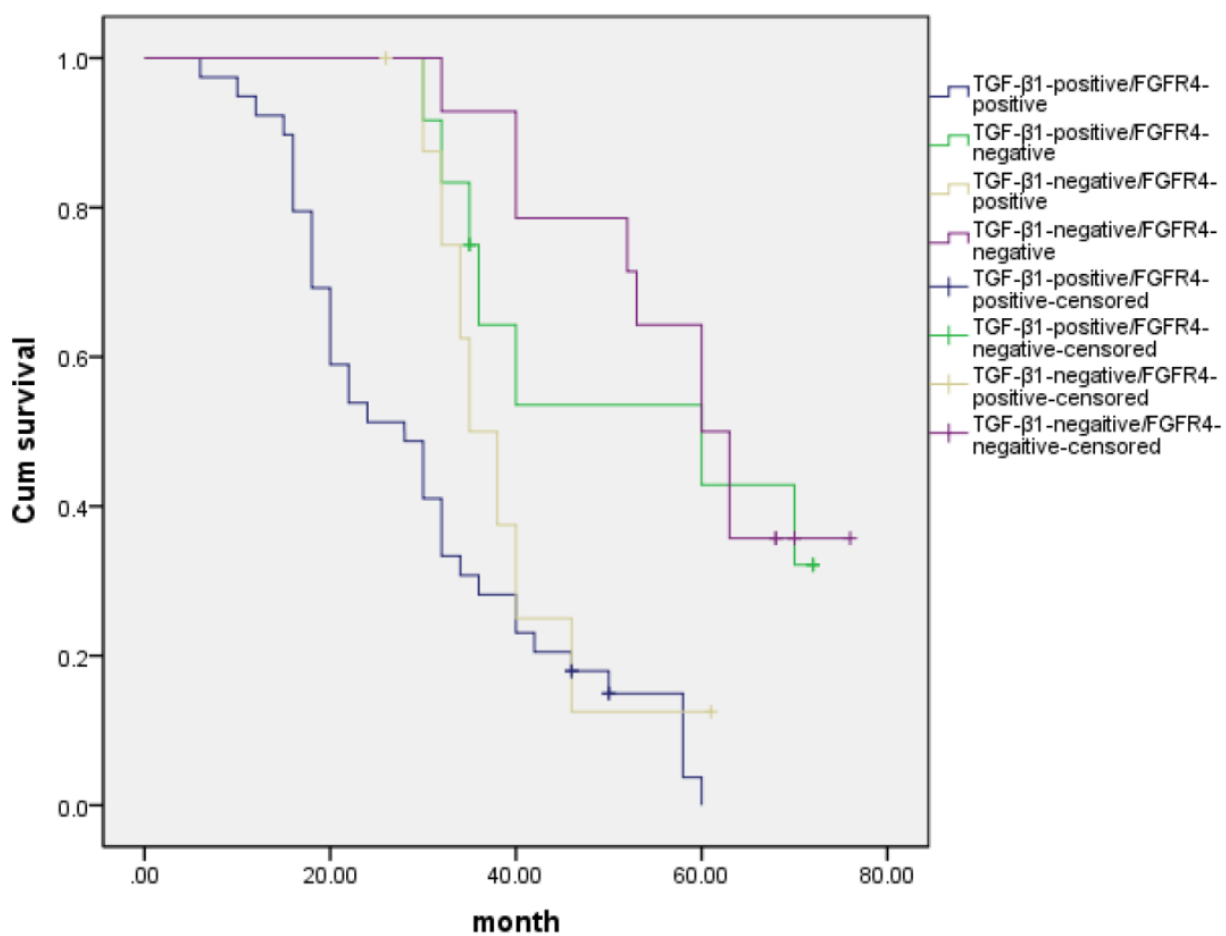

Fig 4. Kaplan- Meier curves with univariate analyses (log- rank) for patients with TGF- $\beta$ I-positive/FGFR4-positive, TGF- $\beta$ I-positive/FGFR4-negative, TGF- $\beta$ I-negative/FGFR4-positive, and TGF- $\beta$ I-negative/FGFR4-negative hepatocarcinoma patients. 


\section{Discussion}

HCC has the worst prognosis among all major cancers. This could be due to the fact that no effective methods of early diagnosis are currently available as well as the lack of effective therapies, resulting in high mortality of patients diagnosed with HCC. Recent molecular investigations have suggested that molecular targeting can be a powerful therapeutic device for treating human malignancies, including liver cancer. Molecular targeting medicines appear to hold great potential in treating liver cancer [19]. We show here that the expression of TGF- $\beta 1$ and FGFR4 is elevated in liver cancer, as compared to normal tissues. These findings provide evidence for the modulatory roles of TGF- $\beta 1$ and FGFR4 in HCC progression and suggest that TGF- $\beta 1$ and FGFR4 may be important and novel therapeutic targets in treating HCC.

Transforming growth factor $\beta$ (TGF $\beta$ ) is a multifunctional cytokine that regulates the proliferation and differentiation of various types of cells. Three subtypes of TGF- $\beta$ receptor, including T $\beta R-1, T \beta R-2$ and T $\beta R-3$, have been identified. TGF- $\beta$ binds to T $\beta$ Rs (serine/threonine kinase receptors), which mediate the intracellular activation of signal transduction pathways through Smad proteins. Studies demonstrated that the TGF- $\beta$ and its receptor are associated with tumors, and TGF- $\beta 1$, as a prototypic member of the TGF- $\beta$ superfamily of signaling molecules, is involved in the regulation of cell growth and differentiation, angiogenesis, immunosuppression, extracellular matrix formation, fibrogenesis, and tumorigenesis [23-24]. The effect of TGF- $\beta 1$ in tumors is complex, TGF- $\beta 1$ is considered as a tumor suppressor gene in the initial stage of tumorigenesis, and growth inhibition by the TGF- $\beta 1$ has been extensively studied in diverse cell types. TGF- $\beta 1$ can selectively induce tumor cell-cycle arrest and apoptosis in hepatic cells [25-27]. However, TGF- $\beta 1$ can enhance growth in the progression of late stage tumors and the possible mechanisms for these growth-enhancing effects includes induced immunosuppression, enhanced angiogeness, and increased peritumoral stroma formation. Li et al reported that TGF- $\beta 1$ affects both proliferation and apoptosis of GC cells through the regulation of p15 and p21, and induces the transient expression of Smad 7 as a negative feedback modulation of TGF- $\beta 1$ signaling [28]. The ability of TGF- $\beta 1$ to induce apoptosis depends to some extent upon the cellular concentration of various TGF- $\beta 1$ receptors [29]. Nevertheless, the possible role of TGF- $\beta 1$ signaling in the simultaneous modulation of HCC proliferation and apoptosis remains unclear.

In our study, TGF- $\beta 1$ was mainly localized in the cytoplasm of HCC cells, staining yellow or brown. A significant difference was observed between TGF- $\beta 1$ expressions levels in HCC and matched peritumoral tissues. TGF- $\beta 1$ expression was related to tumor grade and pathological stage, but not to age, sex and tumor size. These results showed that the expression of TGF- $\beta 1$ increased with the increase of tumor grade. Hence, TGF- $\beta 1$ is not only a growth suppression factor but also has a strong ability to suppress immunity.

Fibroblast growth factors (FGFs) orchestrate a variety of signaling molecule functions by binding to and activating their transmembrane tyrosine kinase receptors (FGFRs). FGFRs have a conserved structure comprising three extracellular immunoglobulin (Ig) domains, a single-pass transmembrane domain and a cytoplasmic tyrosine kinase domain [30]. The FGF/FGFR signaling system plays important roles in cell proliferation, migration, differentiation, morphogenesis, and angiogenesis. FGFR4 is one of the members of the FGFR family that is associated with tumor. Several lines of evidence support this hypothesis that FGFR4 may play an important role in hepatocellular carcinoma. FGFR4 is the predominant FGFR isoform present in human hepatocytes [17]. FGF19 as a high affinity, heparin-dependent ligand for FGFR4 shows exclusive binding to FGFR4. FGF19-induced hepatocyte proliferation has been reported to be uniquely mediated by FGFR4 [31]. It is suggested that FGF19/FGFR4 system plays a critical role in HCC progression [32]. Our findings also showed that the expression of FGFR4 correlate with the prognosis of hepatocarcinoma. We estimated that the detailed mechanism by which FGF19/FGFR4 contributes to the poor prognosis of patients with HCC maybe correlate with TGF- $\beta 1$ signaling. Previous research reported that liver tissue has the highest FGFR4 and KLB transcript levels, and both of these proteins are essential for ligand-stimulated activity by this signaling system [18]. But the role of FGFR4 in oncogenesis is controversial. Some researchers have reported that FGFR4 contributes significantly to HCC progression by modulating a-fetoprotein (AFP) secretion, proliferation, and anti-apoptosis [16]. However in this study, the expression of FGFR4 in HCCs was not significantly correlated to serum AFP levels. Other lines of evidence suggest that the resident hepatocyte FGFR4 is a candidate for limiting hepatoma progression rather than promoting it. The overexpression of FGFR4 is related to an increase in apoptosis and better prognosis [33]. It is possible that contextual factors including the identity and concentration of ligand, as well as the levels of FGFRs and co-receptor expression, might modulate the role of FGFR4 in tumorigenesis.

In particular, our study provides correlations between FGFR4 and TGF- $\beta 1$ in hepatocarcinoma tis- 
sues. Positive expression of FGFR4 or TGF- $\beta 1$ could affect the survival of HCC patients. Univariate and multivariate analyses revealed both TGF- $\beta 1$ and FGFR4 to be the independent prognostic factors in HCCs. It is reported that NSCLC cell lines which induced by TGF- $\beta$ could exhibit FGFR1 expression [34]. Here we estimated the crosstalk between FGFR4 and TGF- $\beta 1$ in hepatocarcinoma. The molecular rationale under the connection need to be further explored.

On the whole, we have demonstrated that intratumoral TGF- $\beta 1$ and FGFR4 expression may be correlated with postoperative survival and relapse in patients with HCC. Our findings suggest that these two proteins may be potential targets for adjuvant therapy. Because the present study was retrospective, the results need to be further validated in future prospective studies.

\section{Acknowledgements}

This study was supported by National Natural Science Foundation of China (81101570), Zhejiang Education Research Project (Y200907097), National College Students' Innovation Training Project (201210343015, 201310343014), Xinmiao Science and Technology Plan of Zhejiang Province (2012R413015), and Wenzhou Science and Technology project (Y20090257).

\section{Abbreviations}

TGF- $\beta 1$, transforming growth factor- $\beta 1$; FGF, fibroblast growth factor; FGFR4, fibroblast growth factor receptor 4; HCC, hepatocellular carcinoma; AFP, a- fetoprotein; TNM, tumor, lymph node, and metastasis; PBS, phosphate-buffered saline; T $\beta$ Rs, transforming growth factor beta receptors.

\section{Competing Interests}

The authors have declared that no competing interest exists.

\section{References}

1. Parkin DM, Bray F, Ferlay J, Pisani P. Global cancer statistics, 2002. CA Cancer J Clin. 2005; 55: 74-108

2. Lau WY, Lai EC. Hepatocellular carcinoma: current management and recent advances. Hepatobiliary Pancreat Dis Int. 2008; 7: 237-257.

3. Bruix J, Sherman M. Management of hepatocellular carcinoma. Hepatology. 2005; 42: $1208-1236$

4. El-Serag HB, Rudolph KL. Hepatocellular carcinoma: epidemiology and molecular carcinogenesis. Gastroenterology. 2007; 132: 2557-2576.

5. Chen YJ, Yeh SH, Chen JT, Wu CC, Hsu MT, Tsai SF, et al. Chromosomal changes and clonality relationship between primary and recurrent hepatocellular carcinoma. Gastroenterology. 2000; 119: 431-440.

6. Imamura H, Matsuyama Y, Tanaka E, Ohkubo T, Hasegawa K, Miyagawa S, et al. Risk factors contributing to early and late phase intrahepatic recurrence of hepatocellular carcinoma after hepatectomy. Hepatol. 2003; 38: 200-207.

7. Caulín C, Scholl FG, Frontelo P, Gamallo C, Quintanilla M. Chronic exposure of cultured transformed mouse epidermal cells to transforming growth factor-beta 1 induces an epithelialmesenchymal transdifferentiation and a spindle tumoral phenotype. Cell Growth Differ. 1995; 6: 1027-1035.

8. Cui W, Fowlis DJ, Bryson S, Duffie E, Ireland $\mathrm{H}$, Balmain A, et al. TGFbeta1 inhibits the formation of benign skin tumors, but enhances progression to invasive spindle carcinomas in transgenic mice. Cell. 1996; 86: 531-542.
9. Portella G, Cumming SA, Liddell J Cui W, Ireland $\mathrm{H}$, Akhurst RJ, et al Transforming growth factor beta is essential for spindle cell conversion of mouse skin carcinoma in vivo: implications for tumor invasion. Cell Growth Differ. 1998; 9: 393-404

10. Frontelo P, González-Garrigues M, Vilaró S, Gamallo C, Fabra A, Quintanilla M. Transforming growth factor beta 1 induces squamous carcinoma cell variants with increased metastatic abilities and a disorganized cytoskeleton. Exp Cell Res. 1998; 244: 420-432.

11. Romero D, Iglesias M, Vary CP, Quintanilla M. Functionalblockade of Smad4 leads to a decrease in beta-catenin levels and signaling activity in human pancreatic carcinoma cells. Carcinogenesis. 2008; 29: 1070-1076.

12. Zeisberg M, Yang C, Martino M, Duncan MB, Rieder F, Tanjore H, et al. Fibroblasts derive from hepatocytes in liver fibrosis via epithelial to mesenchymal transition. Biol Chem. 2007; 282: 23337-23347.

13. Streit S, Mestel D, Schmidt M, Ullrich A, Berking C. FGFR4 Arg388 allele correlates with tumour thickness and FGFR4 protein expression with survival of melanoma patients. Br J Cancer. 2006; 94: 1879-1886.

14. Roidl A, Berger H, Kumar S, Bange J, Knyazev P, Ullrich A. Resistance to chemotherapy is associated with fibroblast growth factor receptor 4 up-regulation. Clin Cancer Res. 2009; 15: 2058-2066.

15. Takahashi A, Sasaki H, Kim SJ, Kakizoe T, Miyao N, Suqimura T, et al. Identification of receptor genes in renal cell carcinoma associated with angiogenesis by differential hybridization technique. Biochem Biophys Res Commun. 1999; 257: 855-859.

16. Ho HK, Pok S, Streit S, Ruhe JE, Hart S, Lim KS, et al. Fibroblast growth factor receptor 4 regulates proliferation, anti-apoptosis and alpha-fetoprotein secretion during hepatocellular carcinoma progression and represents a potential target for therapeutic intervention. Hepatol. 2009; 50: 118-127.

17. Kan M, Wu X, Wang F, McKeehan WL. Specificity for fibroblast growth factors determined by heparan sulfate in a binary complex with the receptor kinase. Biol Chem. 1999; 274: 15947-15952.

18. Lin BC, Wang M, Blackmore C, Desnoyers LR. Liver-specific activities of FGF19 require Klotho beta. Biol Chem. 2007; 282: 27277-27284.

19. Furukawa T. Molecular targeting therapy for pancreatic cancer: current knowledge and perspectives from bench to bedside. Gastroenterol. 2008; 43: 905-911.

20. van Diest PJ, van Dam P, Henzen-Logmans SC, Berns E, van der Burg ME, Green J, et al. A scoring system for immunohistochemical staining: consensus report of the task force for basic research of the EORTC-GCCG. European Organization for Research and Treatment of Cancer-Gynaecological Cancer Cooperative Group. J Clin Pathol 1997: 50: 801-804.

21. Saito H, Tsujitani S, Oka S, Kondo A, Ikeguchi M, Maeta M, et al. The expression of transforming growth factor-beta1 is significantly correlated with the expression of vascular endothelial growth factor and poor prognosis of patients with advanced gastric carcinoma. Cancer. 1999; 86: 1455-1462.

22. Motoda N, Matsuda $Y$, Onda M, Ishiwata T, Uchida E, Naito Z. Overexpression of fibroblast growth factor receptor 4 in high-grade pancreatic intraepithelial neoplasia and pancreatic ductal adenocarcinoma. Int J Oncol. 2011; 38: 133-143.

23. Ueno T, Hashimoto O, Kimura R, Torimura T, Kawaguchi T, Nakamura T, et al. Relation of type II transforming growth factor-beta receptor to hepatic fibrosis and hepatocellular carcinoma. Int J Oncol. 2001; 18: 49-55.

24. Zhang L, Yuan SZ. Expression of c-erbB-2 oncogene protein, epidermal growth factor receptor, and TGFbeta1 in human pancreatic ductal adenocarcinoma. Hepatobiliary Pancreat Dis Int. 2002; 1: 620-623.

25. Masuhara $\mathrm{M}$, Yasunaga $\mathrm{M}$, Tanigawa $\mathrm{K}$, Tamura $\mathrm{F}$, Yamashita $\mathrm{S}$, Sakaida $\mathrm{I}$ et al. Expression of hepatocyte growth factor, transforming growth factor alpha, and transforming growth factor beta 1 messenger RNA in various human liver diseases and correlation with hepatocyte proliferation. Hepatodlogy. 1996; 24: 323-329.

26. Fan G, Ma X, Kren BT, Steer CJ. The retinoblastoma gene product inhibits TGF- beta1 induced apoptosis in primary rat hepatocytes and human $\mathrm{HuH}-7$ hepatoma cells. Oncogene. 1996: 12:1909-1919.

27. Zong L, Qu Y, Xu MY, Dong YW, Lu LG. 18a-glycyrrhetinic acid down-regulates expression of type I and III collagen via TGF-B1/Smad signaling pathway in human and rat hepatic stellate cells. Int J Med Sci. 2012; 9: 370-379.

28. Li X, Zhang YY, Wang Q, Fu SB. Association between endogenous gene expression and growth regulation induced by TGF-beta1 in human gastric cancer cells. World J Gastroenterol. 2005; 11:61-68

29. Lu Y, Wu LQ, Li CS, Wang SG, Han B. Expression of transforming growth factors in hepatocellular carcinoma and its relations with clinicopathological parameters and prognosis. Hepatobiliary Pancreat Dis Int. 2008; 7:174-178.

30. Eswarakumar V, Lax I, Schlessinger J. Cellular signaling by fibroblast growth factor receptors. Cytokine Growth Factor Rev. 2005; 16: 139-149.

31. Xie MH, Holcomb I, Deuel B, Dowd P, Huang A, Vaqts A, et al. FGF-19, a novel fibroblast growth factor with unique specificity for FGFR4. Cytokine. 1999; 11: 729-735

32. Miura S, Mitsuhashi N, Shimizu H, Kimura F, Yoshidome $\mathrm{H}$, Otsuka M, et al. Fibroblast growth factor 19 expression correlates with tumor progression and poorer prognosis of hepatocellular carcinoma. BMC cancer. 2012; 12:56.

33. Huang X, Yang C, Jin C, Luo Y, Wang F, McKeehan WL. Resident hepatocyte fibroblast growth factor receptor 4 limits hepatocarcinogenesis. Mol Carcinog. 2009; 48: 553-562.

34. Thomson S, Petti F, Sujka-Kwok I, Epstein D, Haley JD. Kinase switching in mesenchymal-like non-small lung cancer lines contributes to EGFR inhibitor resistance through pathway redundancy. Clin Exp Metastasis. 2008; 25:834-854. 